\title{
FAST AND ACCURATE SEQUENTIAL INJECTION AMS WITH GATED FARADAY CUP CURRENT MEASUREMENT
}

\author{
M Klein・D J W Mous • A Gottdang \\ High Voltage Engineering Europa B.V., Amersfoort, the Netherlands. Email: info@highvolteng.com.
}

\begin{abstract}
Sequential injection or bouncing has a number of properties which can lead to a reduction of the analysis accuracy if no appropriate measures are taken. A special injection system has been developed in order to eliminate these shortcomings. The influence of source glitches or instabilities on the measured isotopic ratio is substantially reduced by a high cycling frequency. A fast beam-blanking unit guarantees the needed accuracy of the injection periods. Background currents are avoided by synchronizing the current measurement for the stable isotopes with their injection periods. To achieve the required speed and precision of the gated measurement, new instrumentation was developed. The elimination of background contributions allows an efficiency for radiocarbon counting as high as $95 \%$ at a cycling frequency of $100 \mathrm{~Hz}$.
\end{abstract}

\section{INTRODUCTION}

In accelerator mass spectrometry (AMS), the injector system has to select 2 or 3 masses of interest. Unwanted masses are rejected to reduce the measurement background and the beam-current load of the accelerator.

In a sequential injection system, the isotopes are injected one after the other. The vacuum chamber of the injector magnet is electrically isolated. A voltage applied to the chamber changes the energy of the ions that pass through the magnetic field. The voltage determines the mass of the injected ions. The cyclic change of this voltage for the injection of a sequence of isotopes is often referred to as bouncing. Data acquisition for the rare isotope is usually stopped during injection of the stable isotopes, which eliminates background originating from their injection. Sequential injection provides the flexibility to examine virtually all isotopes of the periodic system. The accuracy of the timing of the injection as well as the switching characteristics of the bouncer voltage power supply influence the achievable precision of the analysis. This is of special importance for ${ }^{14} \mathrm{C}$ dating where the highest precision is desired.

In the last 15 years, a number of AMS systems using simultaneous injection have been installed by HVE (Nadeau 1998a/b; Gottdang 1995; Aramaki 2000; Kim 2000; Nakamura 2000). Figure 1 shows a record on precision for these systems as well as for the first dedicated sequential injection ${ }^{14}$ C-AMS system by HVE, which is installed in Lecce, Italy (Calcagnile 2002). The series labeled "13/12 precision" shows the standard deviation of the stable isotope ratio measurement of 6 different targets that are made from the same sample material. "14/12 precision" shows the standard deviation of the rare isotope measurements on these targets. "Statistical error ${ }^{14} \mathrm{C}$ " is the calculated error that arises from the counting statistics. The measured 14/12 precision values scatter around the statistical errors. Apparently, there are no other contributions to the achieved precision (Gottdang 2001); this also holds for the sequential injection AMS system. The data indicates that the achieved precision was limited by counting statistics only and that principally this system allows ${ }^{14} \mathrm{C}$ analysis with higher precision. For further comparison of sequential and simultaneous injection AMS, see Nadeau (2003).

To push the performance of sequential injection AMS to its limits, HVE has optimized the bouncer set-up and its electronics, as described in the following paragraphs.

(C) 2004 by the Arizona Board of Regents on behalf of the University of Arizona Proceedings of the 18th International Radiocarbon Conference, edited by N Beavan Athfield and R J Sparks RADIOCARBON, Vol 46, Nr 1, 2004, p 77-82 


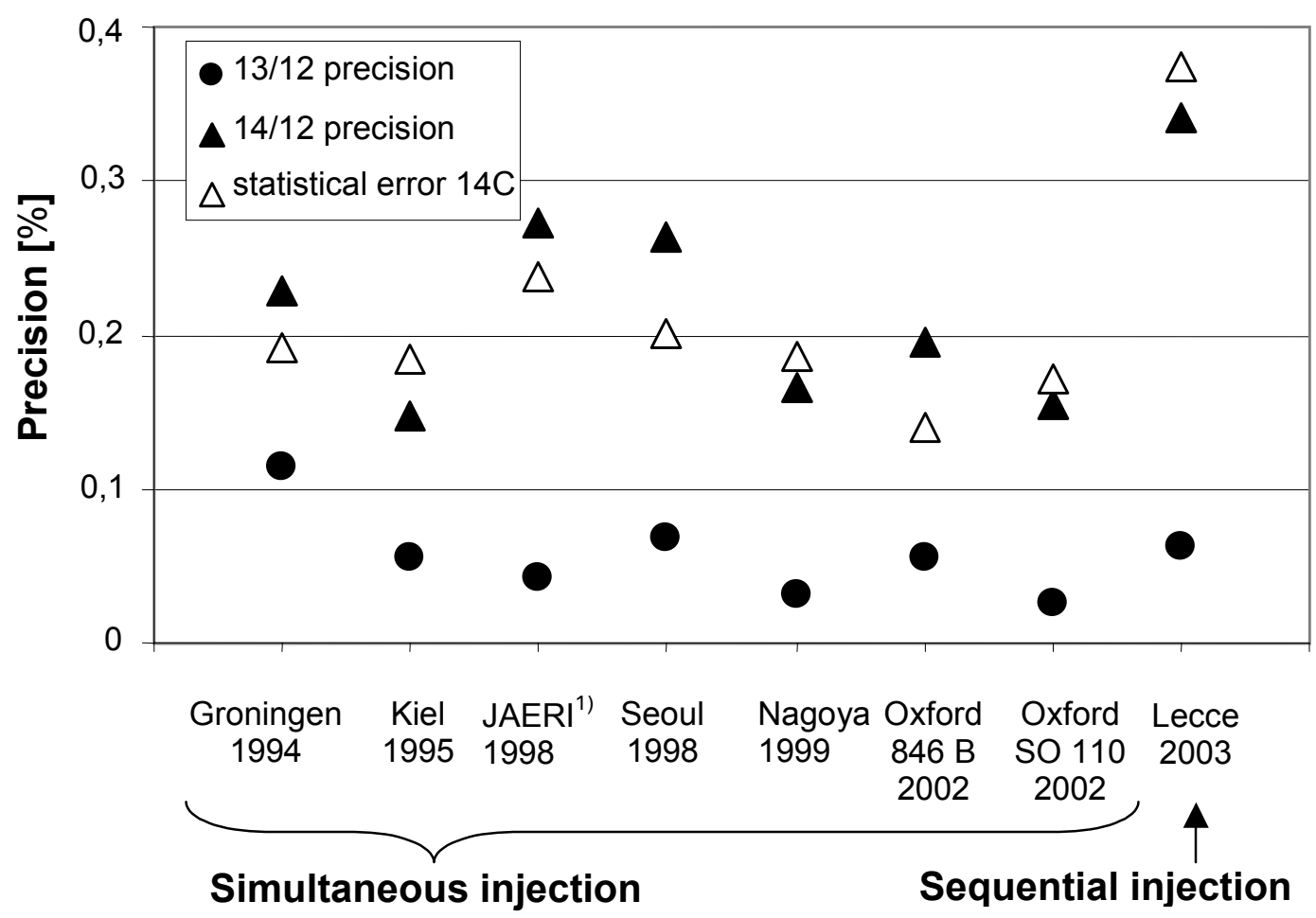

Figure 1 Precision measurements on dedicated ${ }^{14} \mathrm{C}$ AMS systems from HVE. ${ }^{1}$ Refers to the ${ }^{14} \mathrm{C}$ section of the AMS system.

\section{PROPERTIES OF SEQUENTIAL INJECTION DETERMINING ITS PERFORMANCE}

In the following, we concentrate on 3 different properties of bouncing which can each have their own adverse contribution to the achievable precision of the analysis.

\section{Cycling Frequency}

Changes in the system conditions, like source instabilities and glitches, may affect the measurement of the various isotopes differently when they happen fast compared to the injection cycling frequency. For an accurate ratio measurement, fast cycling is required.

\section{Isotope Switching}

During switching between the isotopes, the magnet chamber voltage requires some time to settle. This settling time depends on the involved capacitances and on the characteristics of the power supply used. The voltage variation during the settling time results in an unstable beam position. This will have an influence on the system transmission and, in turn, on the achieved precision. The effect gets more pronounced with higher cycling frequencies when the settling time covers a larger part of the injection period. The settling effects can be avoided with an additional switching system for isotope injection.

\section{Background Currents}

Measurement of the stable isotopes can be influenced by background currents. Figure 2 shows typical Faraday cup currents (charge state $3+$ ) as a function of the analyzing magnet current for the 
injection of masses 12,13, and 14 AMU. The figure shows, apart from the peaks of mass 12 and 13, that a continuum of background currents is present, which is generated by charge exchange processes in the acceleration tubes. In addition, distinct peaks originating from the injection of $\mathrm{CH}_{\mathrm{n}}$ are visible on the traces measured during the injection of 13 and $14 \mathrm{AMU}$. It should be noted that the contribution of $\mathrm{CH}_{\mathrm{n}}$ is not constant, but depends on the hydrogen content of the sample. The error on the measurement that is induced by background currents can be minimized by the choice of injection periods for the stable isotopes. The ${ }^{13} \mathrm{C}$-injection period is usually about 100 times longer than the period for ${ }^{12} \mathrm{C}$. This long time comes to the expense of the ${ }^{14} \mathrm{C}$-injection period and reduces the measurement efficiency. Detailed analysis on the intensities of the background continuum, as well as the peaks resulting from $\mathrm{CH}_{\mathrm{n}}$ molecules, indicated that this error can reach levels as high as $1-2 \%$.

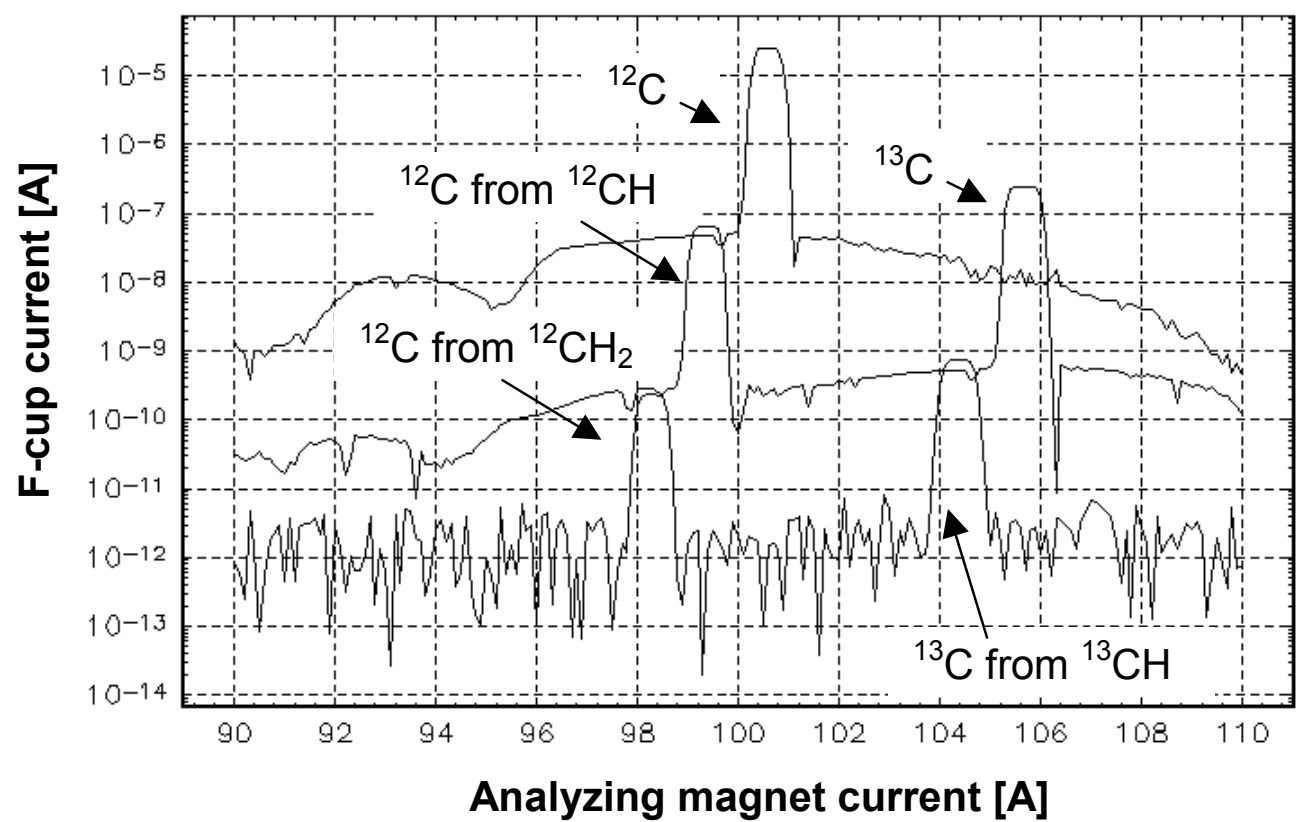

Figure 2 Analyzing magnet scans with mass 12 (upper curve), 13 (center curve), and 14 (lower curve) injected into the accelerator

\section{CHARACTERISTICS OF THE HVE SEQUENTIAL INJECTION SYSTEM}

The newly developed bouncer system is designed for high cycling frequencies to overcome the influence of ion beam instabilities. The adverse effects of the switching process are eliminated by the use of a beam-blanking unit which stops the beam unless the measurement conditions are stable and it defines the injection period with high accuracy. By synchronizing the measurement of the stable isotopes with their injection, the background currents resulting from the injection of the other isotopes are avoided. This allows the use of very short measurement times for the stable isotopes and to achieve a high time efficiency for the counting of the rare isotope.

Figure 3 gives the timing of the measurement process. The upper curve shows the magnet chamber voltage during switching of the isotopes. The voltage settling time is about $100 \mu$ s. During this time, the beam is stopped by a separate ultra-fast beam-blanking unit (second curve). This unit is a steerer acting as a fast switch, which is located between the injector magnet and the accelerator entrance. 
The unit defines the injection periods with nanosecond resolution. The third curve shows the beam intensity of 1 isotope as it reaches its Faraday cup. Some delay resulting from its time of flight is present. The data acquisition time (last curve) for the stable isotopes covers the injection period (taking into account the time of flight), plus additional time for the electronic processing.

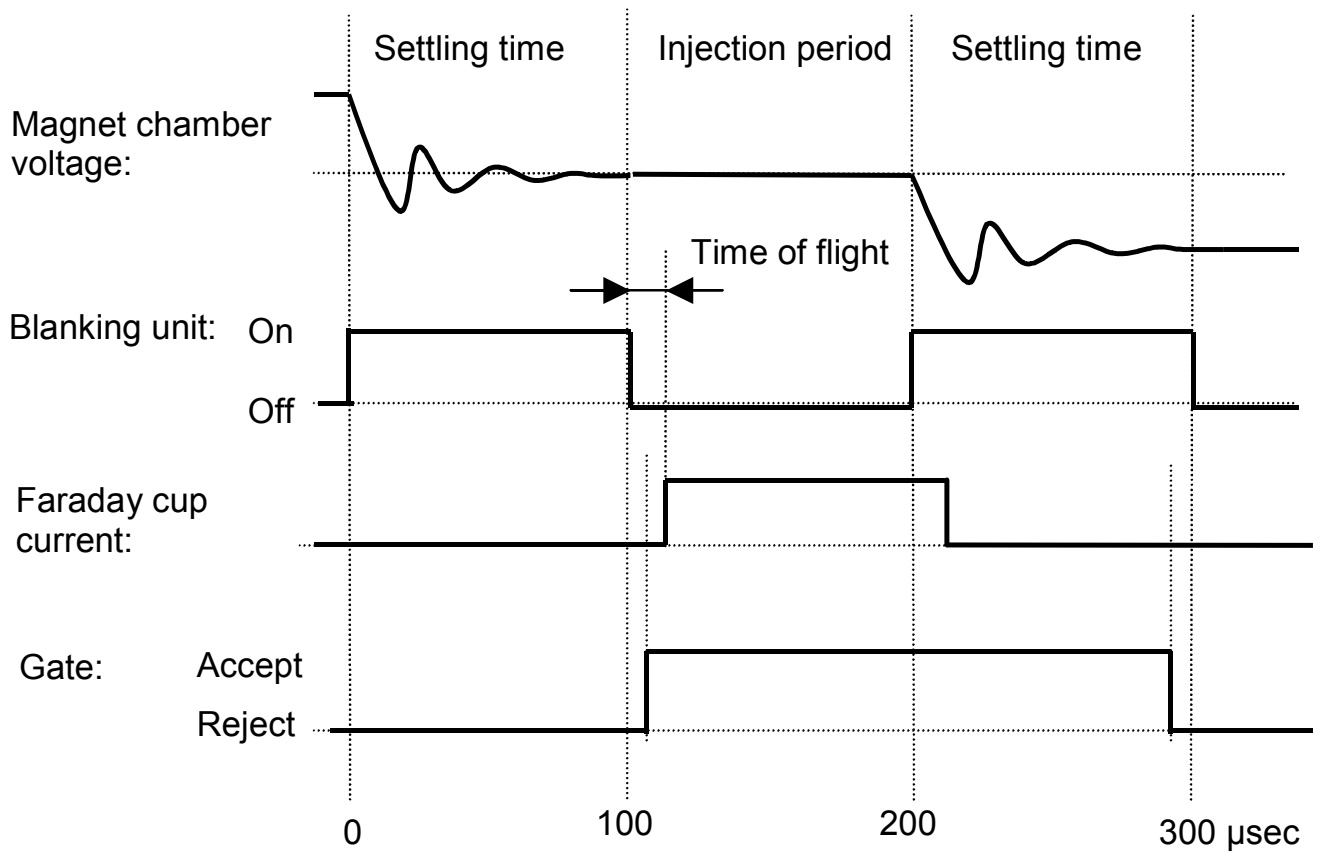

Figure 3 Timing diagram of the stable isotope measurement

For ${ }^{14} \mathrm{C}$ dating, 3 isotopes have to be switched. The settling time totals $3 \times 100 \mu$ s per injection cycle. This limits the achievable cycling frequency to about $1 \mathrm{kHz}$. However, HVE regards a $100-\mathrm{Hz}$ cycling frequency sufficiently high to cope with fast source output variations. Together with typical injection times for ${ }^{12} \mathrm{C}$ and ${ }^{13} \mathrm{C}$ of $100 \mu$ s each, $9500 \mu$ s or $95 \%$ of the total injection time is used for ${ }^{14} \mathrm{C}$ counting. Thus, the sequential injection AMS system almost reaches the rare isotope counting efficiency of the simultaneous injector, in combination with the system inherent advantage of gated isotope measurement for background suppression.

\section{The Gated Current Measurement}

The stable isotopes are measured in shielded Faraday cups with secondary electron suppression. One of the cups (for ${ }^{13} \mathrm{C}$ in case of ${ }^{14} \mathrm{C}$ dating) is internally equipped with 2 slits providing information on the beam position. This slit-error signal is used in a feedback loop that adjusts the terminal voltage of the accelerator such that the beam is kept precisely in the middle of the slit system. The layout of the electronics for the gated current measurement is shown in Figure 4. The electronics unit is mounted in close vicinity of the Faraday cups for low capacitance of the interconnections and to avoid noise and hum.

The total Faraday cup current is converted into voltage. A gate, which is controlled by the bouncer electronics, passes this voltage on to a filter during the measurement intervals. The filtered, virtually 


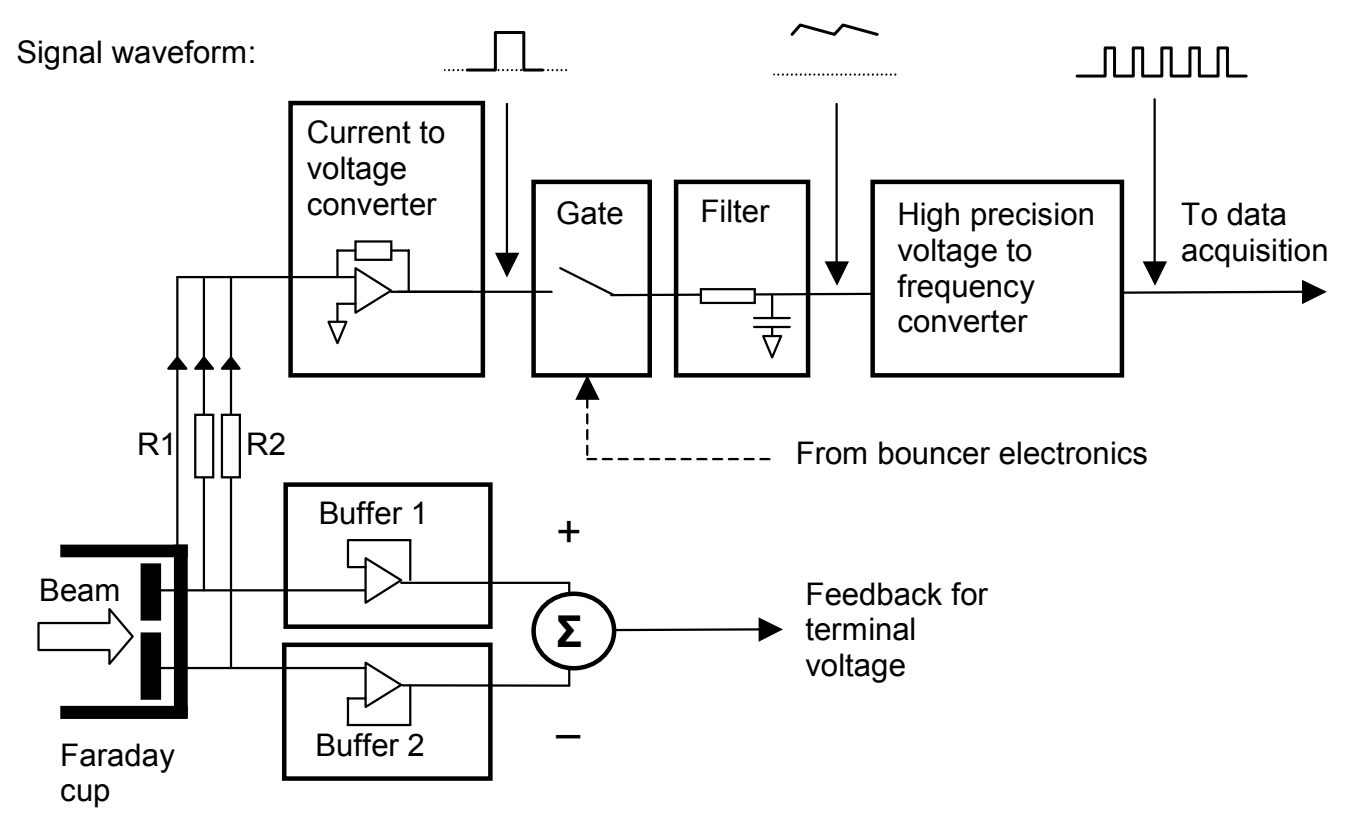

Figure 4 Layout of the electronics for gated Faraday cup current measurements

DC signal is free of background current influences. A high-precision voltage to frequency converter (VFC) converts the signal into pulses, each of them representing a well-defined amount of charge. Two buffers and 2 resistors are used to create the slit-error signal.

Tests have shown that with the high-precision amplifiers and VFCs, the overall precision is in the order of $0.01 \%$. This low value is achieved by using VFCs that are widely applied in isotope ratio mass spectrometry (IRMS) where $10^{-5}$ precision is mandatory. In addition, the application of lowbias and high-speed amplifiers ensures that this accuracy is achieved with Faraday cup currents down to the low $\mathrm{nA}$ range and cycling frequencies up to $1 \mathrm{kHz}$.

\section{CONCLUSION}

HVE has optimized its "bouncing" set-up and electronics to enable isotope ratio measurements with a precision better than $1 \%$. This is achieved by a high cycling frequency to suppress the influence of source output fluctuations. The adverse effects of the bouncer voltage switching on the beam are eliminated by a fast beam-blanking unit, which determines the injection periods of the different isotopes with nanosecond resolution. Gating of the Faraday cup current measurement allows the reduction of the stable isotope injection periods to $100 \mu$ s without background current interferences. In ${ }^{14} \mathrm{C}$ dating, $95 \%$ of the analysis time is used for ${ }^{14} \mathrm{C}$ counting at a cycling frequency of $100 \mathrm{~Hz}$.

\section{REFERENCES}

Aramaki T, Mizushima T, Mizutani Y, Yamamoto T, Togawa O, Kabuto S, Kuji T, Gottdang A, Klein M, Mous DJW. 2000. The AMS facility at the Japan Atomic Energy Research Institute (JAERI). Nuclear Instruments and Methods in Physics Research B 172: 18-23.

Calcagnile L, Quarta G, D’Elia M, Gottdang A, Klein M,
Mous DJW. 2002. High precision radiocarbon measurements with the new sequential injector of the Lecce AMS facility. Proceedings of the AMS-9 conference. Nuclear Instruments and Methods in Physics Research $B$.

Gottdang A, Mous DJW, van der Plicht J. 1995. The HVEE ${ }^{14} \mathrm{C}$ system at Groningen. In: Proceedings of 
the 15th International ${ }^{14} \mathrm{C}$ Conference. Radiocarbon 37(2):649-56

Gottdang A, Mous DJW. 1997. The novel HVEE multielement AMS system. Nuclear Instruments and Methods in Physics Research B 123:163-6.

Gottdang A, Mous DJW. 1998. The characteristics of the HVEE multi-element AMS system. Proceedings of the 15th International Conference on Applications of Accelerators in Research and Industry. Denton, Texas, USA, November 1998. p 652-6.

Gottdang A, Klein M, Mous DJW. 2001. Accelerator mass spectrometry at High Voltage Engineering Europa (HVEE). Radiocarbon 43(2A):149-56.

Kim JC, Lee CH, Kim IC, Park JH, Kang J, Cheoun MK, Kim YD, Moon CB. 2000. A new AMS facility in Korea. Nuclear Instruments and Methods in Physics Research B 172:13-7.

Nadeau MJ, Schleicher M, Grootes PM, Erlenkeuser H, Gottdang A, Mous DJW, Sarntheim JM, Willkomm H. 1998a. The Leibniz-Labor AMS facility at the Chris-
tian-Albrechts-University, Kiel, Germany. Nuclear Instruments and Methods in Physics Research B 123: 22-30.

Nadeau MJ, Grootes PM, Schleicher M, Hasselberg P, Rieck A, Bitterling M. 1998b. Sample throughput and data quality at the Leibniz-Labor AMS facility. In: Mook WG, van der Plicht J, editors. Proceedings of the 16th International ${ }^{14} \mathrm{C}$ Conference. Radiocarbon 40(1):239-45.

Nadeau MJ, Calcagnile L, Rieck A, Quarta G, Grootes PM. 2003. Sequential vs. Simultaneous Injection for AMS ${ }^{14} \mathrm{C}$ dating: Is there a significant difference? Poster presented at the 18 th International ${ }^{14} \mathrm{C}$ Conference.

Nakamura T, Niu E, Oda H, Ikeda A, Minami M, Takahashi H, Adachi M, Pals L, Gottdang A, Suya N. 2000. The HVEE Tandetron AMS system at Nagoya University. Nuclear Instruments and Methods in Physics Research B 172:52-7. 